\title{
Code of Ethics of medical informatics in Asia and
} America

\author{
Hamid Moghaddasi ${ }^{1}$, Hasan Ebrahimpour Sadagheyani ${ }^{1}$
}

\author{
Journal of Research \& Health \\ Social Development \& Health Promotion \\ Research Center \\ Vol. 6, No.5, Nov \& Dec 2016 \\ Pages: 463- 464 \\ DOI: 10.18869/acadpub.jrh.6.5.463 \\ Letter to Editor
}

1. Department of Health Information Management \& Medical Informatics, Faculty of Paramedical Sciences, Shahid Beheshti University of Medical Sciences and Health Services, Tehran, Iran

Correspondence to: Hasan Ebrahimpour Sadagheyani, Department of Health Information Management \& Medical Informatics, Faculty of Paramedical Sciences, Shahid Beheshti University of Medical Sciences and Health Services, Tehran, Iran

Email: Sadageyani@yahoo.com

Received: 16 Dec 2013

Accepted: 24 Nov 2014

How to cite this article: Moghaddasi H, Ebrahimpour Sadagheyani H. Code of Ethics of medical informatics in Asia and America. $J$ Research \& Health2016; 6(5): 463- 464.

\section{Dear Chief in Editor}

Nowadays, using Information and Communication Technology (ICT) in health care with the aim of creating tools for diagnosing and treating diseases has proposed a new debate on the code of ethics. The raised ethical issues are beyond privacy and security, and have been the most important sources of debate and ethical questions in these professions. [1] How to use the diagnostic and therapeutic equipment properly, how to use electronic health records and internet-based genetic and health information, how to use expert systems and medical decision support system, data mining, and how to manage the obtained data are among these common questions. [2] Code of ethics in medical informatics determines the competency and proficiency of the profession by focusing on the ethical implications of medical technologies. [3] Based on the studies conducted in the Americas: Cuba, Mexico, Chile, Brazil, Peru, Uruguay, Argentina, Venezuela, Bolivia, the USA, and Canada have Medical Informatics Associations and are members of the International Medical Informatics Association (IMIA). Among these countries, the USA and Canada from North America own a list of professional code of ethics and other countries follow the codes of the IMIA. Among the Asian countries, China, India, Israel, Japan, Korea, Malaysia, Pakistan, Philippines, Singapore, Sri Lanka, Thailand, and Turkey have the Medical Informatics Association and follow the IMIA code of ethics. Iran established an active Medical
Informatics Association in May 2013 with the support of health information technology and medical informatics professionals. Other countries of Americas, including Antigua, Barbuda, Bahamas, Bermuda, Barbados, Belize, Colombia, Costa Rica, Ecuador, El Salvador, Greenland, Dominica, Grenadines, Guatemala, Guyana, Haiti, Honduras, Jamaica, Nicaragua, Panama, Paraguay, Saint Vincent, Saint Lucia, Suriname, Trinidad, and Tobago, and other countries of Asia, including Afghanistan, Bahrain, Bangladesh, Bhutan, Brunei, Burma, Cambodia, East Timor, Indonesia, Iraq, Jordan, Kazakhstan, Kuwait, Kyrgyzstan, Laos, Lebanon, Maldives, Mongolia, Nepal, Oman, Qatar, Russia, Saudi Arabia, Syria, Tajikistan, Turkmenistan, Uzbekistan, Vietnam, and Yemen do not have any medical informatics associations and follow no specific codes.[3] The IMIA code of ethics that most Asian countries adopt was published under the title of "Professional Code of Ethics for Health Information Professionals" in 2002 and its latest version was released on January 31, 2011 in different languages for free on the association website. The professional code of ethics of the American Medical Informatics Association (AMIA) was approved under the title of "J AM Med Assoc" in 2007 and its latest version was published in 2012 [4]. Canada's Health Informatics Association (COACH) published its first code in 2004. Its brief version of 10 ethical codes is available to the public, but the full version is accessible only to members [5]. Generally, the IMIA code consists of two sections; the first section includes two parts; 
the first part contains a set of fundamental ethical codes that are internationally accepted, and the second part contains a brief list of general codes of informatics ethics used for gathering, processing, storing, communicating, manipulating, and accessing electronic health data and are considered as "general informatics codes". The second section includes a set of codes of conduct. By applying the general codes of informatics ethics by health informatics specialists, these codes are developed in professional activities and are more detailed than the general codes of informatics ethics. The AMIA code has five principles and the $\mathrm{COACH}$ code has 10 codes.

Each of these three lists implies some codes as follows: the importance of health and well-being, protecting the privacy of the individuals, having fair and respectful behavior with community members and promoting these behaviors, protecting information and keeping them confidential, ensuring the integrity and security of the health information and information systems, collaborating with colleagues and medical informatics professionals and members of other professions, performing tasks meticulously, endeavoring to develop technology and respond to the ethical questions arising from logical and correct thinking, continuous efforts to maintain and improve knowledge-based professional competence, preparing and implementing a variety of professional standards to attract the public trust, taking a professional action against conducts contradicting the profession, causing no harm, integrity, equality and justice, responsiveness, usefulness and the principle of impossibility, giving clear and honest notification to the organization and employers and performing tasks carefully, continuous effort to balance our professional obligations through diligent, honest and clear behaviors and respecting our responsibility as a medical informatics specialist.

It is worth noting that the $\mathrm{COACH}$ code does not contain principles such as informed consent, unauthorized disclosure and the legal use of electronic medical records, as well as patients' rights to find information on how we collect, store, obtain, use, and exchange the electronic medical records. However, codes of implementing and maintaining the qualitative standards of the profession in collecting, storing, retrieving, processing, obtaining and exchanging the data, developing informaticsoriented training services in the organization, using tools, techniques, and advanced equipment to perform tasks morally, training individuals about the nature of collecting, storing and using electronic health records, and notifying them of issues, risks, and limitations associated with this matter exist only in the IMIA list.

By comparing the three lists mentioned above, it can be concluded that the IMIA list is much more detailed than AMIA and $\mathrm{COACH}$, which can be due to the IMIA global view to issues and social and cultural differences among countries. The professional ethics for the medical informatics specialists has not yet been developed in our country. This may be due to the fact that medical informatics is a new field in Iran in comparison with developed countries and also the Medical Informatics Association has been newly established and is still in its infancy. However, we can develop a comprehensive collection of codes for Iranian professionals by considering the professional ethics published by the International Medical Informatics Association as the framework, then adjusting it to domestic rules as well as cultural and social norms of the country, and making use of the medical informatics elites, ethics and other related fields.

\section{References}

1- Kazimierz T. Medical informatics ethics and its subject. Roczniki Akademii Medycznej w Biatymstoku2005; 50: 20-2

2- Groen Peter J, Mahootian F, Goldstein Douglas. Medical informatics: emerging technologies, 'Open' EHR systems, and Ethics in the 21st Century. 2008. Open publication.

3- International medical informatics association. The IMIA Code of Ethics for Health Information Professionals [4 screens]. Available at URL:imiamedinfo.org/new2/pubdocs/Ethics_Eng.pdf. Accessed 2012. 21 Jan 2013.

4- Kenneth WG, Samantha A, Eta SB. AMIA's Code of Professional and Ethical Conduct. J Am Med Inform Assoc2013; 20(1): 141-3.

5- COACH, Health Informatics Professional Core Competencies. 2012. Available at URL : www.imiamedinfo.org/new2/node/66.pdf. Access 4 Jun 2014 